\title{
Editorial
}

\section{For an Authentic Reform of Present French Legislation on the Transfer of Enterprises}

\author{
(Without Freedom of Transfer there can be no Freedom of Enterprise) \\ (based on a Beaumarchais quotation)
}

Yann Kergall, Coopers \& Lybrand CLC Juridique et Fiscal, Paris, France

At a time when European Communities are critically concerned with reversing the tide of the disappearance of small and medium sized businesses entailing the loss of jobs, so often caused by badly managed transfers, and when there are strong recommendations put forward by the special Commission ${ }^{1}$ for incentives to the development of a more competitive economy, the current French 1996 Finance Bill seems to ebb from the true mark of actual and sorely needed reform. At the very end of 1995, the 'Conseil Constitutionnel' (High Court in charge of constitutional issues) has decided that the measures relative to business transfers are not complying with the French Constitution and consequently are invalid. Nevertheless, this editorial has been maintained since it is likely that the government will prepare a new draft in this field and that certain points of the cancelled project will be a reference. In addition, the alternative solution proposed at the end of this editorial might be a solution to the constitutional difficulties.

The amendments envisaged are supposedly designed to offer a reduction in the overall tax burden on transfers in order to facilitate their success thereby ensuring continuity of businesses rather than their sale. They can indeed be considered as a positive step in the right direction insofar as they are the mark for the first time of recognition by the French legislator of the link between such continuity, as intended by business owners and management, and employment.

Yet a closer look at the 28 November 1995 of the 1996 Finance Bill is reason to fear that, rather than the serious encouragement of successful transfers through a long hoped for and recommended reform, we are rather being teased with timid measures which serve more as an alibi than as an effective legislative tool. Indeed, the owner of a healthy business faced with the choice between a sale and a transfer would soon see the disappointment of the proposed amendments entailed by the fact that:

- while an initial 50 per cent reduction on the first FF 100 million per share would be applied in the calculation on taxes levied at a 40 per cent rate in direct line to 60 per cent for non relatives, over and above FF 100 million these rates would weigh on the actual value of the enterprise transferred;

- this reduction would only be granted in case of gift or succession of full ownership thereby requiring the donor to totally relinquish, before the age of 65 , what is most often a means of livelihood and work tool;

- the requirement to hold business assets for a period of five years before and after the transfer represents a form of rigidity hardly compatible with the dynamics of today's business economies.

This proposal seems even more likely to fall short of the objectives when compared with existing French tax provisions:

- a 25 per cent reduction in transfer taxes on gifts and partitioned gifts (donations partagés), in the case of a partitioned gift made by a donor under the age of 65 to a descending line relative;

\footnotetext{
' OJEC 94/C 400-(01, Communication of the Commission recommendation of 7 December 1994 on the transfer of small and medium-sized enterprises.
} 
- the possibility of the donor retaining usufruct ownership (usufruit) enabling the enjoyment of enterprise control and dividends and the assessment of transfer taxes on the value of the 'bare' ownership (nuepropriété) (80 per cent of the full ownership if the donor is over 60 and under 70 , or 70 per cent if he is over 50 and under 60 );

- taxes being paid by the donor, which represents a significant decrease in the overall tax burden;

- deferred and apportioned payment of taxes over 15 years spreading out the fiscal cost of the gift.

It would be reasonable to assume that these last two tax alleviations should apply to gifts covered by the 1996 Finance Bill. In this case a candidate for a business transfer could rightly question whether the present measures are not just as favourable as an apparent reduction of 50 per cent - especially since said measures offer the option of retaining usufruct ownership and control.

The next legitimate question raised would then be how the new measures will work as an incentive for business owners to keep their concerns running through successful transfer when they hardly differ from those existing measures having thus far failed to convince owners that transfers for no consideration can be better than sales.

In light of these considerations, one can see rather how the measures proposed will miss the much needed reform mark which had been announced during the recent Presidential campaign.

For authentic reform to take place, we see the alternative solution of an equivalent of the 'British Business Relief' as a means to achieve the stated goal and the recommendations of the EU Commission. This regime offering a conditional exemption on business transfers for no valuable consideration could be applied in France as it is on work tools (notion d'outil de travail) according to the wealth tax definition. In other words, taxes would become payable on the gradual prorata temporis basis where an enterprise is sold before the end of a given time (seven years for example as in the case of the United Kingdom), and would not be due if the enterprise is not sold after such period.

As with the French wealth tax regime, the value of the enterprise would not be assessed for tax purposes at the time of its transfer. Of course, given the context of civil law in France, it would be necessary to effect an assessment of the value of the business for civil law purposes (forced heirship constraint).

This proposal is based on the observance of two simple economic realities:

- the date of transfer of a business for no valuable consideration, through gift or succession, is the least appropriate date of evaluation of the value of the enterprise being transferred; this value can only be truly established when a buyer pays its price;

- an enterprise managed for a long enough period of time, by its successors, whether or not they are heirs, shall have greatly changed with respect to its status at the date of the gift or the succession (depending on the work and competence of the successors). In other words, at the end of a period of tax relief, one could consider that a given enterprise will largely represent the results of those efforts made by its successors who will be greatly encouraged to develop their business.

There are essentially two objections to these measures. The first has to do with the possible losses of tax revenue. However, given the high cost of loss of jobs and weak economic activity connected with small and medium sized businesses being dismantled through sales rather than strengthened through successful transfers, this seeming shortfall could be largely compensated by the benefits of reducing the number of enterprises subject to the risk of liquidation.

The other possible voice of opposition would come from a concern with the social objectives of justice and equitable taxation. This may be clear as far as wealth tax issues are concerned, but here again if taxation of enterprises transferred at present rates weakens the very economic fabric of the nation, with resulting human problems due to the related job losses, surely it is in the interest of all to re-examine the context and find ways to ensure that businesses can survive and grow and that employment will therefore be maintained.

All things considered, while the alternative proposed is not sufficient to address these issues successfully if it is not accompanied by related measures intended to strengthen equity capital, we see it as a necessary and authentic launching pad for future developments.

One of the changes that should be forthcoming is at the level of a widened concept of what the enterprise as a work tool represents. It should be extended to include stable minority shareholder interests and the protection of the usufructuary.

Another obstacle specific to the French context is the prohibition of future succession pacts which would call for a related reform of civil law to legalize family pacts when the succession

intertax

$1996 / 2$ 
involves a business, or enterprise pacts needed in such cases to improve chances of survival and further economic growth and competitivity.

The stakes are high in the framework of a concerted European effort to safeguard employment and foster our economies. Considering that the 1996 French Finance Bill is far from the implementation of the recommendations made, we nevertheless consider that it is a first step in the right direction. But it is also high time to propose the immediate study of the Business Relief Regime as an authentic and necessary reform for France.

In creating and growing their businesses, entrepreneurs are in as much inclined to develop their efforts when they can reasonably expect to have a large freedom of transfer at the time of retirement. We all know that excessive taxation could limit this freedom. So far, the recommended and proposed Business Relief Regime is only the application of part of the freedom of enterprise. 